\title{
Aortic Valve Regurgitation
}

National Cancer Institute

\section{Source}

National Cancer Institute. Aortic Valve Regurgitation. NCI Thesaurus. Code C50861.

The backward flow of blood from the aorta into the left ventricle, owing to insufficiency

of the aortic semilunar valve; it may be chronic or acute. 